Article

\title{
'Evidence' of Neglect as a Form of Structural Violence: Parents with Intellectual Disabilities and Custody Deprivation
}

\author{
Hanna Björg Sigurjónsdóttir * and James G. Rice \\ Faculty of Social and Human Sciences, University of Iceland, 105 Reykjavík, Iceland; E-Mails: hbs@hi.is (H.B.S.), \\ james@hi.is (J.G.R.) \\ * Corresponding author
}

Submitted: 4 January 2018 | Accepted: 19 February 2018 | Published: 17 May 2018

\begin{abstract}
This contribution draws upon the findings from a multi-year project in Iceland entitled Family Life and Disability. One goal of the project was to analyse whether or not parents with intellectual disabilities (ID) experienced differential treatment in custody deprivation proceedings. The dataset consisted of the analysis of publicly available court documents concerning custody deprivation cases from 2012 to 2017. The project later expanded its dataset to include supplementary information provided by parents. The initial findings mirrored that of the international literature, that parents with ID faced disproportionate levels of permanent custody deprivation and prejudicial attitudes from the child protection system. This contribution critically explores the evidence of parenting neglect that forms of basis for custody deprivation in our dataset. Both authors noted a preponderance of evidence in our dataset that appeared strange and at times absurd, and generally did not appear in cases were ID was not a factor. We contend that this evidence played a prejudicial role in the outcome of these cases. In conclusion we argue that the patterned reliance upon this kind of 'evidence' is a form of structural violence which serves to unjustly exclude marginalised groups from the parenting role.
\end{abstract}

\section{Keywords}

child protection; custody deprivation; disability; Iceland; intellectual disability; structural violence

\section{Issue}

This article is part of the issue "Global Perspectives on Disability", edited by Shaun Grech (The Critical Institute, Malta) and Karen Soldatic (Western Sydney University, Australia).

(C) 2018 by the authors; licensee Cogitatio (Lisbon, Portugal). This article is licensed under a Creative Commons Attribution 4.0 International License (CC BY).

\section{Introduction}

This contribution focuses on one particular problematic that emerged during the course of the project Family Life and Disability which was conducted in Iceland from 2014 until 2017. This problem concerned how to analyse some of the odd, strange or at times even absurd evidence of parental neglect that routinely appeared in the analysis of our data. The dataset for this project was a national sample of publicly accessible court documents concerning permanent custody deprivation cases over the years 2002 through to 2012. This was later extended up until the time of writing and also included further supplementary information provided to us by some parents. Our primary, but not exclusive, focus was on cases concerning parents with intellectual disabilities (ID) who had lost custody of their children as the result of actions undertaken by the child protection system. We contend that a careful analysis of the documents pertaining to child protection cases can help to reveal some of the systemic problems underlying how child protection is practiced. The international literature is clear that parents with disabilities, particularly ID, face disproportionate rates of custody deprivation as the result of the entrenched stigmas and negative perceptions held against parents with disabilities and which excludes them from the parenting role. We contend that disability discrimination or prejudice against people with ID can shape crucial decisions in 
the child protection process and this is influential at every stage of the child protection process, from notifications, to parenting assessments, to the implementation and evaluation of support measures and in the final decisions of the cases. In this article, our goal is to demonstrate some of the effects of these biases through a close examination of how some evidence of parental neglect or incompetence is produced in these cases. The analytical framework that follows is intended as an exploration of how we may interpret these findings, as well as to invite debate.

In the data collection and assessment stages of our project we remained perplexed as to why we found such strange evidence of parenting neglect or incompetence predominantly in cases concerning parents with ID, and significantly less so in cases that concerned parents in other situations, such as parents with substance abuse issues. We noted an almost total absence of this kind of evidence in cases that concerned the direct and severe abuse or neglect of children for which there was clear and uncontested evidence that children were in immediate danger or risk in terms of their health, safety or development. It was not until the later stages of the project that we started to realise the possible significance of this finding. We will present some examples of this kind of evidence which exemplifies the patterns that we have noted before turning to a brief case study. The first author has been involved in research pertaining to parents with ID in Iceland for many years. During the course of our more recent project it became apparent, during a reanalysis of some older data, that this kind of 'absurd' evidence about the parenting capabilities of parents with disabilities has been a feature of Icelandic child protection for many years. This contribution will conclude with an analysis of a previously unpublished case study which details the struggles by two parents with ID to retain custody of their newborn child. The details are presented through data collected through interviews with all relevant parties: the parents, some extended family of the parents, the parents' lawyer, the municipal social worker assigned to the case, the prenatal care and maternity ward professionals involved, child protection workers, the disabled persons' ombudsman tasked to safeguard the parents' rights, and the psychologist assigned to evaluate the parents. Informed by the insights drawn from our Family Life and Disability project and the scholarly literature, we will argue that biases, prejudiced assumptions and even fears about the parenting capabilities of people with ID play a significant role in influencing the child protection process, the nature of the evidence collected and the results of unjust outcomes and unnecessary custody deprivation.

\section{Parenting and ID}

The international literature (e.g., Alexius \& Hollander, 2014; Aunos, Goupil, \& Feldman, 2003; Gould \& Dodd, 2014; Lightfoot, Hill, \& LaLiberte, 2010; Lightfoot, Lalib- erte, \& Cho, 2017; McConnell \& Llewellyn, 2000; McConnell, Llewellyn, \& Ferronato, 2006; Reinders, 2008), as well as research in Iceland (Sigurjónsdóttir \& Rice, 2016; Traustadóttir \& Sigurjónsdóttir, 2008), has shown that parents with disabilities, particularly parents with ID, face disproportionate rates of interference from child protection authorities and significant risks of custody deprivation. The literature suggests that fear, prejudice, negative attitudes and discrimination play a significant role in explaining the additional scrutiny from child protection services faced by parents with disabilities. Some scholars (e.g. Alexius \& Hollander, 2014) argue that evidence of direct discrimination in child protection matters is difficult to prove, though they contend that certain practices could indeed be understood as discriminatory. One example, arguably, of direct discrimination in the Icelandic context can be found within the guidelines produced by the national child protection agency. These guidelines define what is meant by neglect and which includes leaving children in the care of a person who is "mentally retarded" (proskaheftur) (Freysteinsdóttir, 2012, p. 8). However, the politics of disability have been changing in Iceland and child protection practices need to reflect these changes, particularly as disability matters are increasingly framed as human rights issues. Iceland ratified the United Nations Convention on the Rights of Persons with Disabilities (UNCRPD) in 2016. Article 23 concerning respect for home and the family states that all forms of discrimination against persons with disabilities, "in all matters relating to marriage, family, parenthood and relationships", need to be eliminated. (UNCRPD, 2006). Not all parents with ID or related impairments lose custody of their children in Iceland. But for those who do, disability status is sometimes cited by the child protection authorities as the primary reason for custody deprivation (e.g. unable to benefit from treatment or training). However, in our experience of cases in which low IQ is referred to, much of the evidence as to the role that IQ plays in parenting is unclear, ambiguous and often indirect and inferred from a compilation from many, often quite dubious, sources that comprise the kind of evidence under discussion here. The accuracy of the instruments used to predict the risks of child abuse or neglect in general have been questioned in the literature and often fail to provide critical information on what kinds of support are effective in specific circumstances (see e.g. Taylor, Baldwin, \& Spencer, 2008). Our contention is that much of the evidence that revolves around the disability status of the parent in various ways speaks more to the ignorance or fears held by the professionals in the system than it does to any real danger faced by their children. We contend that these fears colour the entire process, exaggerating the weaknesses of these parents, minimizing their strengths, and casting doubt upon the effectiveness of support measures. As such it is very difficult for these parents to be treated fairly by the system and to receive the tailored and meaningful support they need to be effective parents. The child protection system need only 
demonstrate a reasonable level of 'risk' of neglect-not even evidence of direct abuse or neglect-to terminate custody. It is here where this kind of evidence plays an important role.

\section{Evidence and Absurdities}

At one point in our research we began to discuss what to do with the 'absurdities'. Early in the process we noticed time and time again statements in our dataset from child protection workers, psychologists conducting parenting assessments, and those hired to supervise and monitor parents under investigation (known as tilsjón in Iceland) examples of what we considered to be 'odd' or 'absurd' evidence. This included such things as the observation there was a cat on the bed in a parent's home, with no explanation as to its significance or relevance for an investigation of parenting neglect. Or that there were fingerprint smudges on a window pane, which one would normally expect in a household with children. Or a comment from an anonymous source that a child's teeth were broken and in poor shape, yet a report from a healthcare worker from the same time period made no such observation. Or a comment that there was a dresser in a child's bedroom full of small toys that the child had been rooting through, with no further explanation of its import and leaving the reader adrift as to why this was problematic and what it had to do with the matter at hand. Or the observation that there was a 'Russian lightbulb' in the parent's living room, which in Iceland refers to a naked lightbulb without a cover; we later discovered that this 'Russian lightbulb' was merely part of a lighting system in place when the parent moved in and never used. We could easily fill an entire article with these kinds of mundane, seemingly unimportant, sometimes contradictory and most certainly odd observations that we routinely encountered in our project data. We initially left this kind of 'evidence' of parenting neglect unanalysed, reserving it for humorous anecdotes to be used in classrooms and conference presentations about the difficulties that parents with ID in Iceland faced during their encounters with the child protection system. However, as we continued to find more examples of this kind of material we began to ponder its significance.

We consulted a legal professional, concerned that there were matters at play that were beyond our professional knowledge base. We raised this with a professor of law who dismissed this line of questioning because, from her point of view, it is not relevant. A comment made in an assessment of a home by a child protection worker that there was a cat on the bed might be strange, but it would never be a justification for custody deprivation and in her view not worthy of our attention. This is indeed true, as none of this kind of evidence, as individual statements of fact, could ever constitute child abuse or neglect, or be grounds for custody deprivation. Social work in general is concerned with evidence in the form of patterns, not isolated examples (Munro, 2008). There is, for example, nothing in the guidelines issued by the national child protection agency in Iceland concerning neglect pertaining to cats on beds or smudges on windows, and these kinds of observations would most likely never prompt a notification to the system of parenting neglect, let alone form the basis for an investigation. In our estimation, child protection workers and case managers would not see this as evidence either, but rather as merely objective descriptions of the parents' homes and behaviours. Yet the extent to which we encountered this kind of material on a regular basis continued to trouble us, considering as well how often it appeared in cases of parents with ID compared with other parents. Questions remained as to why these kinds of statements were made in the first place and deemed important enough to be entered into a logbook or parenting assessment. Our tentative conclusion is that it was the disability status of the parents that somehow allowed for this evidence to exist and to be given the weight of significance within parenting assessments and reports and which served to present an overall image of parental neglect and incompetence.

When we encountered examples of this 'absurd evidence' in the research process, to call it absurd would admittedly be charitable. During our research sessions we would shake our heads and exclaim something to the effect that this was 'so stupid'. Yet 'stupid' is hardly an appropriate academic framework for analysis and we remained stymied as to what to do with this kind of data. In the absence of clear or direct evidence of neglect these cases were, in our analysis, at their core about the system's response to parents with ID who were rendered ineligible for the parenting role on the basis of disability. Lacking direct or convincing evidence of neglect, the narrative produced in order to justify and legitimate the decision to terminate custody was a composite of different sources of information collected during the investigation and assessment process. This composite collection of seemingly trivial things in isolation served to become, in tandem, the much sought after pattern of neglect or incompetence.

\section{Structural Violence and System Abuse}

One possible analytical framework in order to understand this kind of evidence and how it came to be can be found in the work of the anthropologist David Graeber (2012). Graeber, in his analysis of bureaucracy, does not resist invoking the term 'stupid' and 'stupidity' in order to understand the everyday forms of disempowerment produced by the workings of bureaucracy, but he uses the term in a very specific way and in conjunction with a theory of violence. The child protection system in Iceland, comprised of a national level agency and a series of local, municipal level committees, is most certainly a bureaucratically organised system and can be argued to exhibit many of the traits and practices that Graeber defines as 'stupid'. However, far from a simplistic analysis or childish name-calling, Graeber develops a sophisti- 
cated analysis predicated on the notion of 'structural violence' that we feel aptly describes the power relations that these parents are subjected to. Graeber's work challenges our early assumption that the absurd evidence we encountered was primarily the result of a lack of training, a lack of appropriate education or, simply put, a form of incompetence or 'stupidity'. Graeber, considering the classic work on power and bureaucracy from Weber to Foucault, notes that despite their differences these scholars shared the assumption that this form of power was rational, ordered, purposeful and very effective. Our error was interpreting this evidence as irrational rather than as a different form of rationality.

Violence, like stupidity, is a common, everyday term that in the context of the analysis that Graeber puts forth could be easily misconstrued. Graeber is clear that violence takes many forms. It is generally accepted that bureaucratic agencies routinely apply 'force'; they make us do things on a regular basis that we may not want to, such as pay taxes, trim our hedges, and observe a myriad of seemingly nonsensical by-laws. Repeated infractions may result in warnings, fines and possibly custodial arrangements for a continued lack of compliance. These are all forms of force and Graeber contends that force is "just a euphemistic way to refer to violence" (Graeber, 2012, p. 112). While warnings or fines from a municipal agency about a hedge not being trimmed properly or putting out garbage too early or mixing paper with plastic in a recycling bin may not appear to be a form of violence, in this sense they can be construed as such. A court order to permanently remove custody of child from a birth parent is a clearer form of violence. In the context of parenting with intellectual disability, Booth and Booth (1998) have referred to this as 'system abuse', as they contend that a system intended to protect and support vulnerable families has instead wrought harm and destruction. This often occurs in the form of low-level daily injustices which is not reducible to a single act or actor, but which can result in dramatic outcomes such as permanent child custody deprivation. Following Booth and Booth, we contend that the outcome of custody deprivation is only the more observable and apparent form of this systemic violence, but the underlying process itself is comprised of a series of more mundane forms of ongoing practices that are not often held up for inspection. To avoid the confusion with the common association of violence with physical violence conducted by a human agent, social scientists have preferred to frame this as 'structural violence', especially in the context of marginalized populations. Graeber summarizes structural violence, drawing upon the earlier work of Johann Galtung (1969), as "any institutional arrangement that, by its very operation, regularly causes physical or psychological harm to a certain portion of the population, or imposes limits on their freedom" (Graeber, 2012, p. 112).

We are fully aware that the official mission statement of the child protection authorities in Iceland, as elsewhere, tasks such agencies with harm reduction con- cerning children. If we can consider the family to be a social-cultural institutional arrangement, the child protection system can be seen as an agent that acts against structural violence applied toward children and this is an endeavour that we strongly support. However, we also need to consider the forms of structural violence that are routinely applied toward persons with disabilities, and parents with ID in particular, by this system that is supposed to support them. What we observe in our research are not just actions against individuals, or occurrences within specific cases, but patterns of structural violence against marginalized parents that share commonalities, such as the factor of disability. We observe this occurring on a routine basis and not just in the context of the 'absurdities' under consideration here. There is a high degree of collusion among various institutions and it must be remembered that many of the allies of the parents, such as lawyers and even family, often defer to the opinions of professionals whose voices are generally treated as representing the official interpretation of events. There is perhaps no greater form of violence permitted under civil law than permanently removing children from birth parents. It is a violent act, and one which has far reaching consequences for the parents, their extended families, and the children who in many cases are placed into foster care. Placed into this framework this provides strong argumentation that permanent custody deprivation must only occur under the most serious of situations in which the health, security and development of children is in immediate danger or with strong evidence of serious risks of such. The analysis of structural violence also demands a rigorous and critical approach to analysing child protection practices, such as how investigations are conducted, evidence is collected and analysed, and support is implemented and monitored, especially so pertaining to marginalized parents. It is the context of structural violence that helps to explain the existence of this 'absurd' or 'stupid' evidence of neglect and its significance, without which we merely have a body of strange observations made by those who collect information about parents on behalf of the child protection system. It is also not helpful to dismiss the descriptions of child protection staff and allied professionals about cats on beds or Russian lightbulbs as nonsensical, stupid or trivial comments, or to dismiss the individuals who make and note these observations as less than intelligent, as they are not. Graeber contends that it is structural violence which allows this 'stupidity' to exist and thrive in the first place. In our context, it is the culturally patterned hostility toward parents with ID which informs child protection work and which in turns allows this information to be perceived as significant and meaningful evidence of neglectful parenting. The observations that support these views, no matter it seems how absurd, are accepted as part of the narrative of these parents. As Graeber argues:

It is not so much that bureaucratic procedures are inherently stupid, or even that they tend to pro- 
duce behavior that they themselves define as stupid, but rather, that they are invariably ways of managing social situations that are already stupid because they are founded on structural violence. (Graeber 2012, p. 112)

\section{A Case Study Example}

In order to illustrate some of these processes at work, we have decided to present in some detail a case study that was originally collected by the first author and subsequently re-analysed in light of our current findings placed into Graeber's analytical framework. This particular case study affords a level of detail about a specific case that would not be apparent from court records alone as it also draws upon interview material with all relevant parties. It also is an excellent example of the matter under discussion and it illustrates that little has changed in Iceland as it exhibits the same patterns found within our more recent dataset. Graeber argues that he does not intend to characterise bureaucracies and their staff and actions as 'stupid' in the simple sense, but that the social situations can themselves be said to be stupid in the first place because they are "founded on structural violence" (Graeber, 2012, p. 112). Our case study appears to fit well with Graeber's analysis. The case involved a couple in their twenties who became a 'case' when the woman's mother contacted the local social services seeking advice on behalf of her daughter, as the couple were having their first child and they both had mild ID and would need some support. Before the due date, however, the mother became ill and had to have a caesarean which resulted in her having to stay in the hospital for 10 days to recover. The case concluded with the newborn being removed from the parents 11 days after birth and being placed into a temporary shelter, followed by an expedited process which led to permanent custody deprivation; the parents' attempts to contest the process were not successful. Over the course of these events it is clear that numerous factors of 'stupidity' led to this outcome. Many of the professionals in their reflections upon the case cited the lack of inter-agency cooperation as a primary factor in the outcome. For example, the original social worker from the municipal social services began planning a support system to implement before the child was born. Once the case moved from being governed by the local social services to that of children's protection, this form of support was no longer available under this other system and the parents were not able to get the kind of long-term, specialised support they needed. In another context, the lack of inter-agency cooperation and the lack of continuity in how a case is worked when it moves from one agency to another could be analysed as an outcome based upon poor planning and service management. However, what makes this case 'stupid' in Graeber's sense is that the parents not only had to contend with poorly organised services, but a deeper form of structural violence that allowed this 'stupidity' to thrive and ultimately determine the outcome of custody deprivation as the result of the fears and prejudices that revolved around the category of intellectual disability.

The lack of inter-agency cooperation certainly did not help the situation, but in analysing the interview material it is apparent that the prejudices, fears, misconceptions, and lack of knowledge or training in this area concerning ID and parenting was the significant factor which produced a good deal of absurd evidence and all but ensured this kind of outcome. Where cooperation did occur, such between the parents' lawyer and the disabled persons' ombudsman, this harmonious relationship (as it was described by the lawyer) seemed to be driven by the tacit acceptance the child would probably be better off with foster parents due to their perception of the parents' disabilities and lack of capability. The fact that the parents' own lawyer and the ombudsman felt this way, when it is their job to advocate on behalf of the parents, illustrates the structural violence inherent in the system that the parents had to negotiate from the outset. Both the father and the mother's mother commented upon this. The latter, after describing a very formal and solemn meeting hosted by children's protective services, noted: "It was so strange; it was as if our lawyer was representing the child protection service and not my daughter and her partner. No one appeared to be supporting us". This is a consistent pattern in our larger experience that the fears are so great among support professionals about the dangers that parents with ID pose to their children that many will favour the view of the system, tacitly or explicitly. The parents' lawyer argued that he felt he had no choice when confronted with reports from healthcare workers and child protection staff but to accept their results: "As a lawyer I had to draw a line somewhere, put away my legal power and trust professionals". Here is an outcome produced as the result of structural violence, 'stupidity' in Graeber's specialised sense. It is of course rational to trust professionals in one sense, but with a close examination of the case data it is clear that this trust is misplaced.

The analysis of the data reveals quite clearly that there were vast differences in professional knowledge concerning intellectual disability in general and ID and parenting in specific. The gross injustice is that it is the voices of those who appeared to be the least knowledgeable that were given prominence. The professionals involved, ranging from social workers to midwives, prenatal care nurses, to maternity unit workers, child protection staff and legal professionals all held their own specialised disciplinary knowledge, but most either displayed good knowledge of the issues, or admitted their own lack of knowledge in this area was a problem. Children's protective services was the only agency that consistently maintained their 'professionalism' in this area and did not appear to be self-critical, even when it became clear that the case manager had little contact with the parents and the staff of the shelter, tasked to surveil and evaluate the parents, had little knowledge in this 
area as well. The initial social worker was adamant that support measures at the least had to be between 3 to 6 months in duration to be effective, including basic support such as housing and finance, along with specialised support for parent training and education for parents with ID, which the couple appeared happy to receive. With the unexpected emergency caesarean, the lack of liaison with the maternity unit and with the social worker out of the country at the time, a panic seemed to ensue within the hospital. The staff were uncertain what to do when the parents were about to be discharged without any apparent support measures up and running and in place. Under pressure to move the process forward, and under advice from the social worker, the matter was transferred to child protection where the only support available under that system was a supervised flat for training parents (which was booked at the time) or else temporary shelter with limited contact with the parents. Both options fell far short of what social services envisioned. Both the social worker, and an infant nurse with experience with parents with ID, scoffed at these measures as a recipe for failure. The infant nurse commented:

I consider a three-month period in the training home the minimum time required for these parents....All parents with their first child need a lot of support to learn to care for their child. Parents with learning difficulties are no different, they just need more time and support.

What is striking is the lack of knowledge on the part of other agencies that generally went unrecognised when the decision was made to terminate custody. A member of the hospital's maternity unit, whose reports were given significant prominence, simply did not know what was available or even needed for parents with this kind of impairment: "What other help and assistance could they get outside the hospital? We didn't know and it was extremely frustrating when social services abdicated their responsibility". This person continued: "Trying to assess the case without the information and knowledge in the field of learning disability makes the whole task enormous". Even within the child protection system it is clear that there was little appreciation for the needs of parents with ID. The child protection case manager described the two workers at the temporary shelter and training facility as 'experienced' yet appeared satisfied that the parents were given only four weeks to demonstrate their capability as parents. The staff at the shelter concurred: "We believe the training period was long enough....We don't believe longer time would have changed anything".

Not only did the ignorance about what constitutes meaningful and individually tailored support play a critical role in producing the outcomes, there was a surprising level of candidness among some of those involved about the prejudice about ID as a factor. The parents of course saw this for what it was and noted the paternalism with the support system as problematic, let alone the open hostility they later encountered in the child protection system. The father, for example, balked at the social worker's insistence that they needed support with things such as shopping, when he was eager to learn about parenting. He commented: "We always did these things by ourselves. They [social services] were making us much more disabled than we are". He argued, as probably all first-time parents do, what he needed help with was taking care of an infant: "I didn't know anything about babies but the way we were treated I feel like they expected us to be born into the parental role". The lack of knowledge about intellectual disability ensured the production of absurd statements. For example, in the view of the staff of the maternity ward, the parents were essentially perceived as children. As one worker put it: "We soon recognised how they were like small children themselves who could not assess their child's needs accurately....There were many things in their behaviour that made us feel like they were children looking after a child". Others, such as workers in the child protection system, perceived the mother as barely able to articulate her thoughts. This is a markedly different assessment from those with experience with persons with ID, such as a pre-natal health specialist who described the mother as having "slight learning difficulties". The child protection workers at the shelter, whose negative assessment played a pivotal role in the custody deprivation process, acknowledged preconceptions and misconceptions of the parents as playing a role in their work, citing the information they received from the maternity unit in specific:

The picture painted from the hospital was painted in very dark colours, darker colours than it actually was. It caused difficulties because we didn't know them [the parents] and we were told that their ability was very little and that they couldn't learn. That wasn't right.

Given the dominance of these views of the parents it is unlikely that any report could possibly present an objective and unbiased view of their capabilities and support needs. Those with more informed and progressive views complained that they were rarely, if ever, consulted once the case became a child protection matter.

An additional absurdity is that the disability status of the parents was also selectively invoked or acknowledged. The same workers who received the 'dark picture' of the parents at times insisted that they treat them like any other parent, forgetting that these parents may require specialised educational or training methods ("We always had to tell her exactly what she had to do. It was not enough, like it is with most parents, just to say you just do this or that"). This also appeared to be the case when the parents' legitimate frustrations were dismissed or misinterpreted. Throughout the case there was constant evidence that the parents were getting mixed messages about breast-feeding, or not; when 
to hold the child and how, or not. This would be confusing for any new parents, let alone for parents of an infant they only had limited access to and during which time they were under intense scrutiny ("We were watching them all the time, especially her, we just sat the whole day watching her", said a shelter worker). Not only was the factor of ID at times selectively forgotten, and the artificial scenario under which they were supposed to demonstrate parenting skills, so was the basic context itself. Two weeks after giving birth to her first child under difficult circumstances, the mother was struggling with numerous and powerful bureaucratic entities that threatened to permanently remove her child, all the while she was still recovering from a major operation and fatigued. Only the driving narrative that she was ineligible for the parenting role as the result of her impairment itself could explain this lacuna within the child protection system concerning her situation. The continued complaints that the mother was withdrawn, listless, passive, and lacked energy played a significant role in the final outcome (said a shelter worker: "We would not have trusted her to be alone with the child, in the beginning she couldn't carry it up the stairs") and there was little attention paid to the context under which these observations were produced.

\section{Concluding Remarks}

The end result of this case, like many others we have analysed over the course of our larger project, arose as the result of numerous factors, but the link which bound these factors together is the negative and fearful perception of intellectual disability and parenting. We are not suggesting that the system should not respond to parents with support needs; quite the contrary. The system also needs to respond to international human rights treaties that Iceland is a party to, such as the UNCRPD, which calls for the elimination of discrimination against person with disabilities "in all matters relating to marriage, family, parenthood and relationships" (UNCRPD, 2006). But it is clear that inter-agency cooperation and human rights treaties are not enough if key actors within the system lack knowledge and experience in this area, and the lack of knowledge is filled with shared prejudices and misconceptions. A 'stupid' outcome, in Graeber's (2012) sense, is inevitable without the willingness to be critical and to interrogate preconceptions and prejudice. Above all, there needs to be a recognition that the process can be a form of system abuse and a product of structural violence. This was well put by the parents' lawyer from the case study who commented: "I believe the parents needed trauma counselling at the hospital when the child was taken temporarily and then again at the final custodial removal stage." Trauma is, by definition, a sudden physical or psychological shock as the result of a form of violence and trauma is what these parents experienced. Without an honest interrogation of how the child protection system, broadly speaking, re- sponds to parents with ID, as well as other marginalised groups, child protection will remain to be a deeply flawed and problematic process.

\section{Acknowledgements}

The authors acknowledge the support of the University of Iceland's research fund (Rannsóknarsjóður HÍ) for this project.

\section{Conflict of Interests}

The authors declare no conflict of interests.

\section{References}

Alexius, K., \& Hollander, A. (2014). Care assessments concerning involuntary removal of children from intellectually disabled parents. Journal of Social Welfare and Family Law, 36(3), 295-310.

Aunos, M., Goupil, G., \& Feldman, M. (2003). Mothers with intellectual disabilities who do or do not have custody of their children. Journal on Developmental Disabilities, 10(2), 65-79.

Booth, T. A., \& Booth, W. (1998). Growing up with parents who have learning difficulties. London: Routledge.

Freysteinsdóttir, F. J. (2012). Skilgreiningar-og flokkunarkerfi i barnavernd (SOF). (2nd ed.). Retrieved from http://www.bvs.is/media/skjol/SOFA4.pdf

Galtung, J. (1969). Violence, peace, and peace research. Journal of Peace Research, 6(3), 167-191.

Gould, S., \& Dodd, K. (2014). 'Normal people can have a child but disability can' $t$ ': The experiences of mothers with mild learning disabilities who have had their children removed. British Journal of Learning Disabilities, 42(1), 25-35.

Graeber, D. (2012). Dead zones of the imagination: On violence, bureaucracy, and interpretive labor. The 2006 Malinowski memorial lecture. HAU: Journal of Ethnographic Theory, 2(2), 105-128.

Lightfoot, E., Hill, K., \& LaLiberte, T. (2010). The inclusion of disability as a condition for termination of parental rights. Child Abuse \& Neglect, 34(12), 927-934.

Lightfoot, E., Laliberte, T., \& Cho, M. (2017). A case record review of termination of parental rights cases involving parents with a disability. Children and Youth Services Review, 79(C), 399-407.

McConnell, D., \& Llewellyn, G. (2000). Disability and discrimination in statutory child protection proceedings. Disability \& Society, 15(6), 883-895.

McConnell, D., Llewellyn, G., \& Ferronato, L. (2006). Context-contingent decision-making in child protection practice. International Journal of Social Welfare, 15(3), 230-239.

Munro, E. (2008). Effective child protection. London: SAGE.

Reinders, H. S. (2008). Persons with disabilities as par- 
ents: What is the problem? Journal of Applied Research in Intellectual Disabilities, 21(4), 308-314.

Sigurjónsdóttir, H. B., \& Rice, J. G. (2016). Stigmatic representation of intellectual disability and termination of parental custody rights. In K. Scior \& S. Werner (Eds.), Intellectual disability and stigma (pp. 77-90). London: Palgrave Macmillan.

Taylor, J., Baldwin, N., \& Spencer, N. (2008). Predicting child abuse and neglect: Ethical, theoretical and methodological challenges. Journal of Clinical Nurs- ing, 17(9), 1193-1200.

Traustadóttir, R., \& Sigurjónsdóttir, H. B. (2008). The 'mother' behind the mother: Three generations of mothers with intellectual disabilities and their family support networks. Journal of Applied Research in Intellectual Disabilities, 21(4), 331-340.

UN General Assembly. (2006). The Convention on the rights of persons with disabilities and its optional protocol. New York, NY: United Nations General Assembly.

\section{About the Authors}

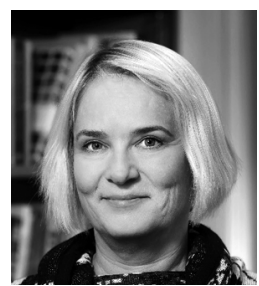

Hanna Björg Sigurjónsdóttir graduated from the University of Sheffield, UK, in 2005. She is currently a Professor in Disability Studies at the University of Iceland and a member of the Centre for Disability Studies at the University of Iceland. Much of her research has focused on families headed by parents with intellectual disabilities and their children. She collaborates with Dr. James Rice in the project Family Life and Disability, which is supported by the University of Iceland's Research Fund from 2014 to 2017.

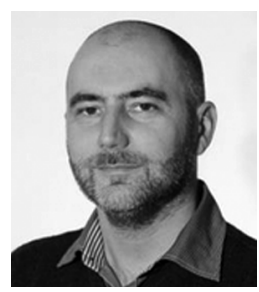

James G. Rice is a Canadian anthropologist who graduated from the Memorial University of Newfoundland, Canada, in 2007. He is currently an Assistant Professor of Anthropology, as well as member of the Centre for Disability Studies at the University of Iceland. He is a collaborator with Dr. Hanna Björg Sigurjónsdóttir in the Family Life and Disability project, which is supported by the University of Iceland's Research Fund from 2014 to 2017. 